\title{
Influence of changes in humidity on dry temperature in GPS RO climatologies
}

\author{
J. Danzer ${ }^{1}$, U. Foelsche ${ }^{1,2}$, B. Scherllin-Pirscher ${ }^{1}$, and M. Schwärz ${ }^{1}$ \\ ${ }^{1}$ Wegener Center for Climate and Global Change (WEGC), University of Graz, Graz, Austria \\ ${ }^{2}$ Institute for Geophysics, Astrophysics, and Meteorology/Institute of Physics (IGAM/IP), University of Graz, Graz, Austria \\ Correspondence to: J. Danzer (julia.danzer@uni-graz.at)
}

Received: 22 April 2014 - Published in Atmos. Meas. Tech. Discuss.: 4 June 2014

Revised: 31 July 2014 - Accepted: 6 August 2014 - Published: 9 September 2014

\begin{abstract}
Radio occultation (RO) data are increasingly used in climate research. Accurate phase (change) measurements of Global Positioning System (GPS) signals are the basis for the retrieval of near-vertical profiles of bending angle, microwave refractivity, density, pressure, and temperature. If temperature is calculated from observed refractivity with the assumption that water vapor is zero, the product is called "dry temperature", which is commonly used to study earth's atmosphere, e.g., when analyzing temperature trends due to global warming. Dry temperature is a useful quantity, since it does not need additional background information in its retrieval. However, it can only be safely used as proxy for physical temperature, where moisture is negligible. The altitude region above which water vapor does not play a dominant role anymore, depends primarily on latitude and season.

In this study we first investigated the influence of water vapor on dry temperature RO profiles. Hence, we analyzed the maximum altitude down to which monthly mean dry temperature profiles can be regarded as being equivalent to physical temperature. This was done by examining dry temperature to physical temperature differences of monthly mean analysis fields from the European Centre for Medium-Range Weather Forecasts (ECMWF), studied from 2006 until 2010. We introduced cutoff criteria, where maximum temperature differences of $-0.1,-0.05$, and $-0.02 \mathrm{~K}$ were allowed (dry temperature is always lower than physical temperature), and computed the corresponding altitudes. As an example, a temperature difference of $-0.05 \mathrm{~K}$ in the tropics was found at an altitude of about $14 \mathrm{~km}$, while at higher northern latitudes in winter it was found at an altitude of about $9-10 \mathrm{~km}$, in summer at about $11 \mathrm{~km}$.
\end{abstract}

Furthermore, regarding climate change, we expect an increase of absolute humidity in the atmosphere. This possible trend in water vapor could yield a wrongly interpreted dry temperature trend. As a consequence, we performed a model study, investigating the increase in height of the transition region between moist and dry air. We used data from the fifth phase of the Coupled Model Intercomparison Project (CMIP5), analyzing again monthly mean dry temperature to physical temperature differences, now from the years 2006 to 2050. We used the highest emission scenario RCP8.5 (representative concentration pathway), studying all available models of the CMIP5 project, analyzing one internal run per model, with the goal to identify the altitude region where trends in dry temperature can be safely regarded as reflecting trends in physical temperature. From all models we therefore choose a selection of models ("max 8" CMIP5 models), which showed the largest trend differences. As a result, our trend study suggests that the lower boundary of the region where dry temperature is essentially equal to physical temperature rises about $150 \mathrm{~m} \mathrm{decade}^{-1}$.

\section{Introduction}

The Radio occultation (RO) technique gains information about the physical properties of a planetary atmosphere by detecting a change in a radio signal when it passes through this atmosphere. With the installment of the Global Positioning System (GPS) constellation this principle could be applied to scan earth's atmosphere. Using the GPS frequencies $L_{1}(1575.42 \mathrm{MHz})$ and $L_{2}(1227.62 \mathrm{MHz})$, the RO technique provides high-quality profiles in the upper troposphere and 
lower stratosphere (UTLS) since 1995; see e.g., Kursinski et al. (1997). It has the advantage of all-weather capability, high vertical resolution, and global coverage. The high data quality and long-term stability make RO data suitable for climate applications.

The climate monitoring capability has first been demonstrated in simulation studies (e.g., Leroy et al., 2006; Ringer and Healy, 2008). Due to the high consistency of RO data from different satellites (Hajj et al., 2004; Schreiner et al., 2007; Foelsche et al., 2011) and a comparatively small structural uncertainty (Ho et al., 2012; Steiner et al., 2013), trend studies could already be successfully carried out based on real data (Steiner et al., 2009; Schmidt et al., 2010; Lackner et al., 2011). In contrast to applications in numerical weather prediction, where parameters close to the observed quantities, such as bending angles, are used in the assimilation, in climate applications all atmospheric parameters need to be considered, since there are regions in the atmosphere, which will, e.g., not show trends in the bending angle, but in temperature (Foelsche et al., 2008b). In that respect it is important to understand the various influences in trends of the atmospheric parameters such as residual influences by the ionosphere (Danzer et al., 2013), or changing water vapor content in the atmosphere, which is the focus of this study.

During an RO event the phase of the transmitted electromagnetic signal, detected at a receiving low earth orbit (LEO) satellite, gets measured. The phase difference between the transmitted and received signal, along with precise orbit and velocity information of the GPS and LEO satellites, is the starting quantity in the data analysis. The processing steps towards the atmospheric parameters of the neutral atmosphere involve geometric optics in regions where moisture is negligible (e.g., Kursinski et al., 1997) and wave optics in regions where humidity grows in importance (e.g., Gorbunov, 2002; Jensen et al., 2003). Furthermore an ionospheric correction at bending angle level needs to be applied (Vorob'ev and Krasil'nikova, 1994). From bending angle profiles one can go via an Abel transform (Fjeldbo et al., 1971) to refractivity profiles, involving an integral up to infinity. However, at higher altitudes (about $\geq 35 \mathrm{~km}$ ) the signal-to-noise ratio gets comparably large at bending angle level. Furthermore, the observational data have a limited extent in altitude (about $80 \mathrm{~km}$ ). Hence, the bending angle profiles need some background information, which could be given by climatological models or by meteorological data (e.g., European Centre for Medium-Range Weather Forecasts, ECMWF). Continuing from refractivity, it is possible to retrieve the atmospheric parameters of the neutral atmosphere, such as density, pressure, and temperature. A general and detailed description of the RO technique and the processing chain can be found in Kursinski et al. (1997).

In the troposphere the humidity in the atmosphere increases, and hence refractivity contains temperature and humidity information. In the analysis of RO data it has become quite common to retrieve dry atmospheric parameters if humidity is negligible. Dry parameters can be used as proxy for physical parameters down to a certain altitude, with the advantage of needing no additional background information in their retrieval. However, the retrieval of physical atmospheric profiles, like physical temperature, physical pressure and humidity, requires always a priori information (moist air retrieval) (Healy and Eyre, 2000).

It is reasonable to analyze dry atmospheric parameters instead of physical parameters in regions where moisture is negligible. In this study the focus lies on monthly mean differences between dry and physical temperature profiles. For single months a first investigation was already done by Foelsche et al. (2008a) and Scherllin-Pirscher et al. (2011), but a systematic analysis was not yet performed. Based on ECMWF analysis data (2006-2010) we investigated to what extent it is valid to study dry temperature profiles as proxy for physical temperature and we also wanted to understand spatial and seasonal dependencies of differences between those two.

Furthermore, we raised the question if changes in dry temperature in observational RO data can correctly be interpreted solely as changes in temperature, or if changes in humidity also affect the trend results. Trends need to be studied on a longer timescale in order to understand the changing influence of water vapor in the atmosphere. Hence, we studied Coupled Model Intercomparison Project (CMIP5) model data from 2006 until 2050, using the highest emission scenario. The goal was to understand the maximal possible development of the height increase of the transition line, i.e., its trend, by studying models with large humidity.

Summarized, this study aims to understand current transition height between dry and moist air and provides a safe trend estimate for future scenarios. Section 2 describes the data sets in use for the two emphases of the investigation. Furthermore, it introduces the dry temperature retrieval in Sect. 2.2 and the analysis method in Sect. 2.3. The results are given in Sect. 3, where we also consider different averaging methods for the analysis fields and discuss the minimum to maximum deviations for transition lines for all models. Conclusions are drawn in Sect. 4.

\section{Data and method}

\subsection{ECMWF data and CMIP5 model data}

We utilized monthly mean ECMWF analysis fields from 2006 to 2010 to study differences between dry and physical temperature. The fields were used in T42L91 resolution, since the T42 horizontal resolution matches the resolution of RO data $(\sim 300 \mathrm{~km})$. They were given on 91 vertical levels (L91), except data in January 2006 have only been available on 60 vertical levels (L60). The extracted fields were temperature $(T)$, specific humidity $(q)$, and atmospheric pressure $(p)$, as a function of geopotential height $\left(z_{\mathrm{g}}\right)$. The calculation 

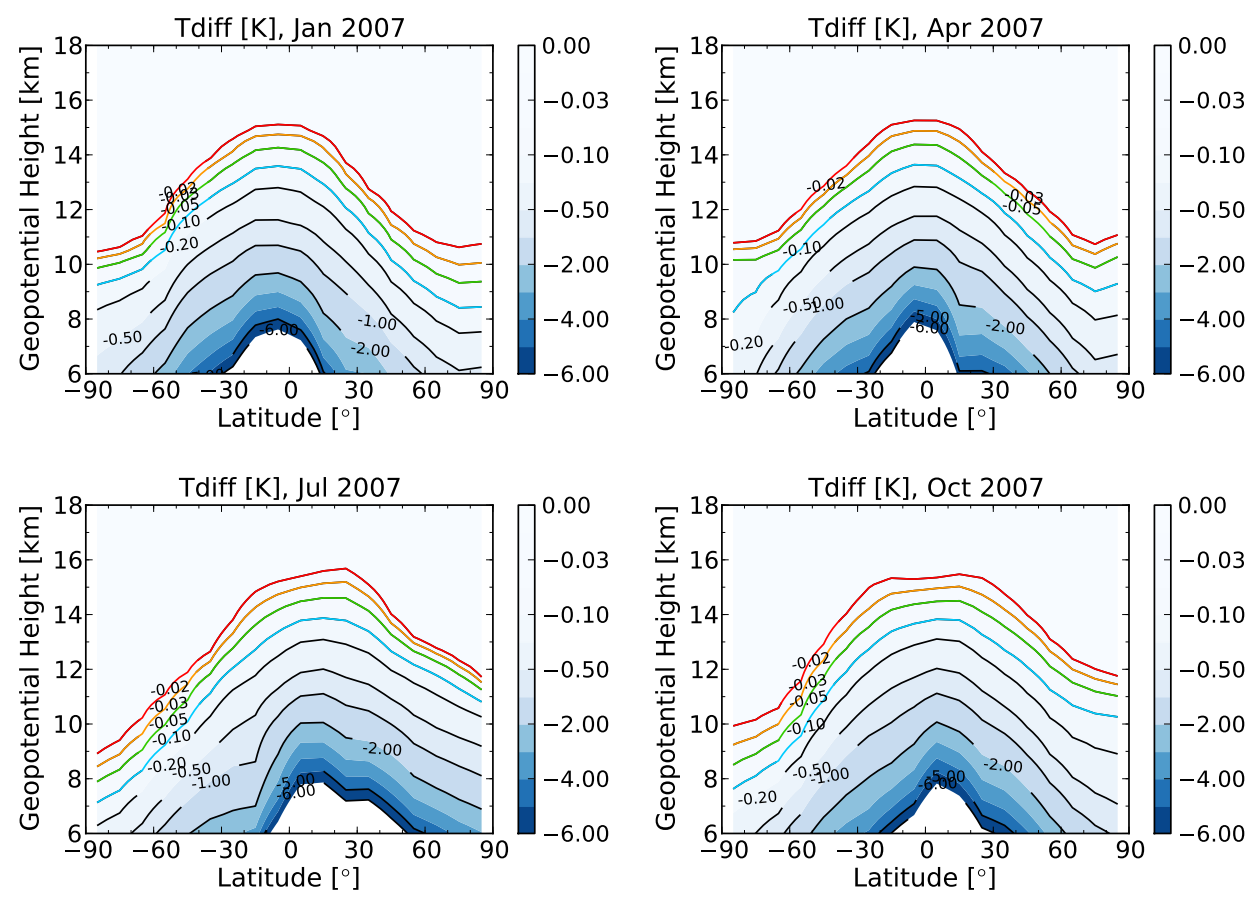

Figure 1. Difference between dry and physical temperature $\left(T_{\text {diff }}\right)$ for ECMWF mean climatological fields. January 2007 (top left), April 2007 (top right), July 2007 (bottom left), and October 2007 (bottom right). The colored lines mark $T_{\text {diff }}=-0.1,-0.05,-0.03$, and $-0.02 \mathrm{~K}$.

of refractivity and dry temperature was performed with the EGOPS (End-to-End Generic Occultation Performance and Processing System) software version 5.5 (Fritzer et al., 2009) analog to Sect. 2.2, stored on a $2.5^{\circ} \times 2.5^{\circ}$ latitude-longitude grid. Afterwards, the resulting fields were interpolated on a $200 \mathrm{~m}$ grid, from 0 to $30 \mathrm{~km}$.

To estimate trends in humidity on a longer timescale, we studied RCP8.5 (representative concentration pathway) scenario simulations for the first half of the 21 st century, using data from the CMIP5 data portal (http://cmip-pcmdi.llnl. gov/cmip5/; Taylor et al., 2009, 2011; CLIVAR Exchanges, 2011). We employed the highest emission scenario RCP8.5 out of four (RCP8.5, RCP6, RCP4.5, RCP2.6), studying one internal run per model. Components of uncertainties in longterm-trend studies are composed of the model formulation, the emission scenario, and internal variability. Studies for CMIP3 (Meehl et al., 2007) showed that until the mid-21st century, the model formulation shows the most important fraction of uncertainty, while the contributions of emission scenario and internal variability are smaller (see e.g., uncertainty analysis over Europe by Prein et al., 2011; Hawkins and Sutton, 2009). At the end of the 21st century the emission scenario gains in importance (see e.g., Fig. 1, by Knutti and Sedlacek, 2013). By studying model data until 2050 we kept the two uncertainties of emission scenario and internal variability small.
In general, RCPs contain not only emission scenarios, but also information about concentration of greenhouse gases and aerosols (see detailed description of RCPs in Van Vuuren et al., 2011). The RCP8.5 scenarios begin 2006, continuing until 2300, having a target radiative forcing of $8.5 \mathrm{~W} \mathrm{~m}^{-2}$ in the year $\sim 2100$. We downloaded simulation data of altogether 38 general circulation models (GCMs), given in Table 1. After an initial study of all models, we have chosen a selection of eight models ("max 8" CMIP5 models, highlighted in Table 1), which had the properties in common to show highest transition lines between dry and moist air. The objective was not to explore the best estimate of a climate scenario, which usually is realized by choosing models close to a multimodel mean (Pierce et al., 2009); instead, the study focuses on high-end simulations, i.e., the upper boundary of the possible influence of humidity on dry temperature trends.

From the CMIP5 database we derived on a monthly timescale data sets from 2006 until 2050 of $T, q$, and $z_{\mathrm{g}}$, given on $p$ levels. Horizontal resolution and the number of pressure levels depend on the modeling center, the latter reaching typically from about 1000 to $10 \mathrm{hPa}$. The study was performed using $10^{\circ}$ zonal mean fields, converted from pressure levels to geopotential height levels. Geopotential height levels were interpolated from 0 to $30 \mathrm{~km}$, on a $200 \mathrm{~m}$ grid. The calculation of refractivity and dry temperature from $T$, $q$, and $z_{\mathrm{g}}$ was performed as explained in Sect. 2.2. 
Table 1. List of all GCMs with emission scenario RCP8.5 from the CMIP5 database in alphabetical order. The bold font highlight the reduced set of CMIP5 models (“max 8”).

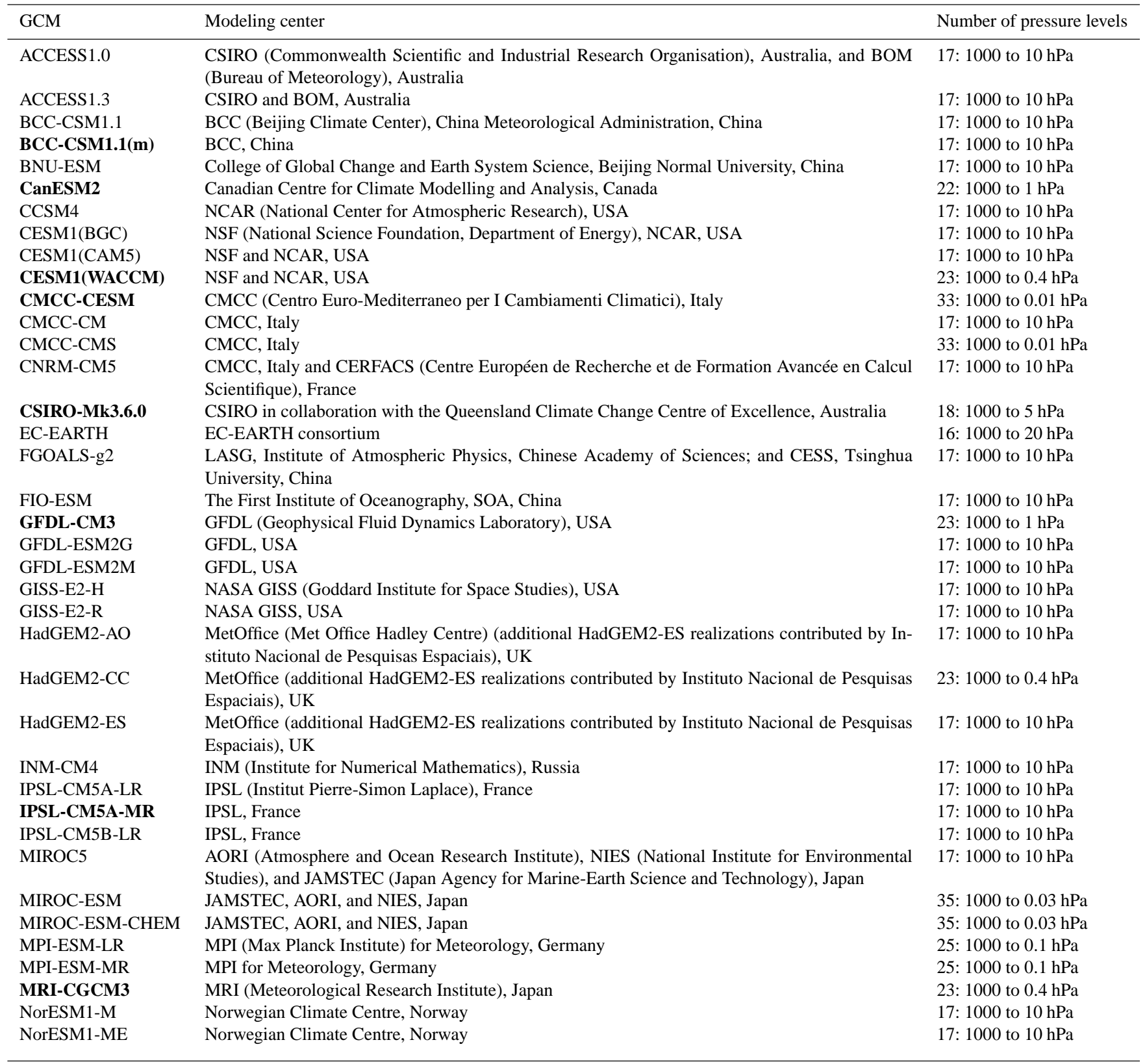

\subsection{Retrieval of dry temperature}

RO data allow for the retrieval of profiles of atmospheric parameters such as bending angle $\alpha$, refractivity $N(N=$ $10^{6}(n-1)$, with $n$ being the refractive index), $p$, and $T$. The core RO variable, $N$, derived from GPS signals depends on conditions of dry atmosphere, water vapor, ionosphere, and on atmospheric scattering from liquid water. To first order it is given by Smith and Weintraub (1953):
$N=77.6 \frac{p}{T}+3.73 \times 10^{5} \frac{e}{T^{2}}-4.03 \times 10^{7} \frac{N_{\mathrm{e}}}{f^{2}}+1.4 \mathrm{~W}$,

where $p$ is the atmospheric pressure (in $\mathrm{hPa}$ ), $T$ is the temperature (in $\mathrm{K}$ ), $e$ the partial pressure of water vapor (in $\mathrm{hPa}$ ), $N_{\mathrm{e}}$ is the electron density (in electrons $\mathrm{m}^{-3}$ ), $f$ is the transmitter frequency (in $\mathrm{Hz}$ ), and $W$ is the mass of condensed water in the atmosphere (in $\mathrm{g} \mathrm{m}^{-3}$ ). The ionospheric contribution is ignored since the ionospheric correction already happens on bending angle level (Vorob'ev and Krasil'nikova, 

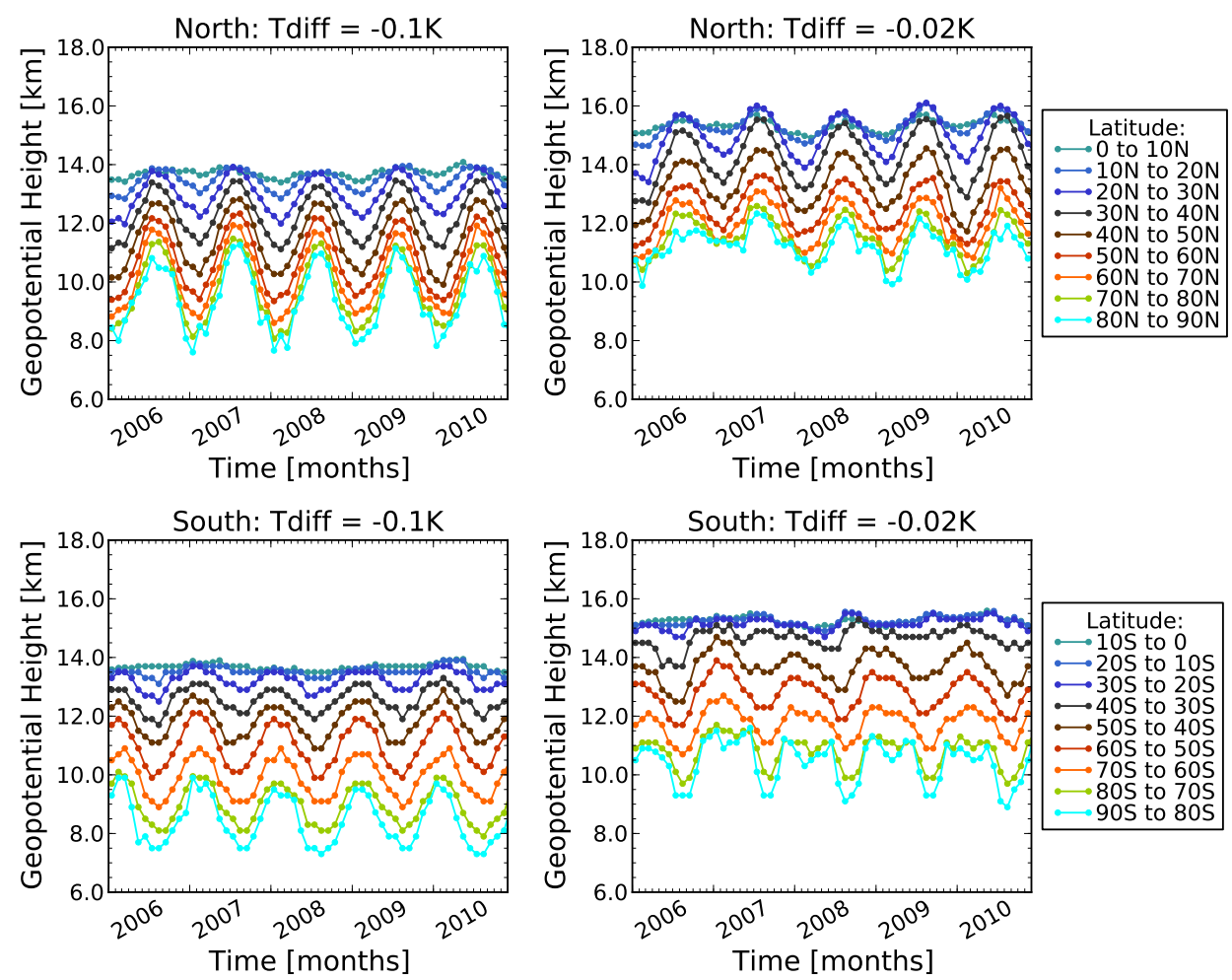

Figure 2. Temporal evolution of differences between dry and physical temperature ( $\left.T_{\text {diff }}\right)$ from 2006 to 2010 , based on ECMWF mean climatological fields. The left column shows the temporal evolution of $T_{\text {diff }}=-0.1 \mathrm{~K}$, while the right column shows $T_{\text {diff }}=-0.02 \mathrm{~K}$.

1994). However, in the upper stratosphere small ionospheric residuals remain, see e.g., Danzer et al. (2013), but in the troposphere they do not play a dominant role. The last term of Eq. (1) can be neglected, since it is small compared to the others. So we find the remaining two terms being the dry and wet contribution; the former due to the induced polarization of the dry constituents of air, and the latter due to the orientation polarization of the water vapor molecules. $N$ is now given by

$N\left(\varphi, \lambda, z_{\mathrm{g}}\right)=$

$77.6 \frac{p\left(\varphi, \lambda, z_{\mathrm{g}}\right)}{T\left(\varphi, \lambda, z_{\mathrm{g}}\right)}+3.73 \times 10^{5} \frac{e\left(\varphi, \lambda, z_{\mathrm{g}}\right)}{T^{2}\left(\varphi, \lambda, z_{\mathrm{g}}\right)}$,

where we emphasize its dependence on latitude $\varphi$, longitude $\lambda$, and geopotential height $z_{\mathrm{g}}$.

In order to estimate the contribution of water vapor on refractivity we calculated dry temperature $\left(T_{\mathrm{dry}}\right)$. We used the parameters $T, p$, and $q$ of the extracted ECMWF and CMIP5 fields to calculate $N$. First, $e$ needed to be evaluated, $q$. The partial pressure of water vapor is given by (for simplicity emphasizing only the vertical dependence $z_{\mathrm{g}}$ of the fields)

$e\left(z_{\mathrm{g}}\right)=\frac{p\left(z_{\mathrm{g}}\right) \cdot q\left(z_{\mathrm{g}}\right)}{a_{q}+b_{q} \cdot q\left(z_{\mathrm{g}}\right)}$ with

$a_{q}=\frac{R_{\mathrm{dry}}}{R_{\mathrm{wv}}} \quad$ and $\quad b_{q}=1-a_{q}$,

and $R_{\mathrm{dry}}$ being the specific gas constant of dry air, $R_{\mathrm{wv}}$ the specific gas constant of water vapor, and $q$ being the specific humidity. Inserting Eq. (3) in Eq. (2) allowed us to calculate the refractivity from the ECMWF and CMIP5 fields.

For the calculation of dry atmospheric parameters the second term of Eq. (2) is neglected. We find, for dry temperature,

$T_{\text {dry }}\left(z_{\mathrm{g}}\right)=77.6 \frac{p_{\text {dry }}\left(z_{\mathrm{g}}\right)}{N\left(z_{\mathrm{g}}\right)}$.

In order to calculate $T_{\text {dry }}$ we first needed to calculate dry pressure $p_{\text {dry }}$ by using the hydrostatic integral and the state equation of an ideal gas. We obtain

$p_{\text {dry }}\left(z_{\mathrm{g}}\right)=\frac{M_{\text {dry }}}{77.6 R} \int_{z_{\mathrm{g}}}^{\infty} N\left(z_{\mathrm{g}}^{\prime}\right) \cdot g\left(z_{\mathrm{g}}^{\prime}\right) \mathrm{d} z_{\mathrm{g}}^{\prime}$,

where $M_{\text {dry }}=28.964 \mathrm{~kg}(\mathrm{kmol})^{-1}$ is the mean molecular mass of dry air, $R=8.314 \mathrm{~J}(\mathrm{~K} \mathrm{~mol})^{-1}$ is the universal gas constant, and $g\left(z_{\mathrm{g}}^{\prime}\right)$ is the acceleration of gravity, which is a function of geographic latitude and height.

Finally, we have determined all input parameters which are needed to calculate dry temperature, while physical temperature was obtained from the downloaded fields. From now on 

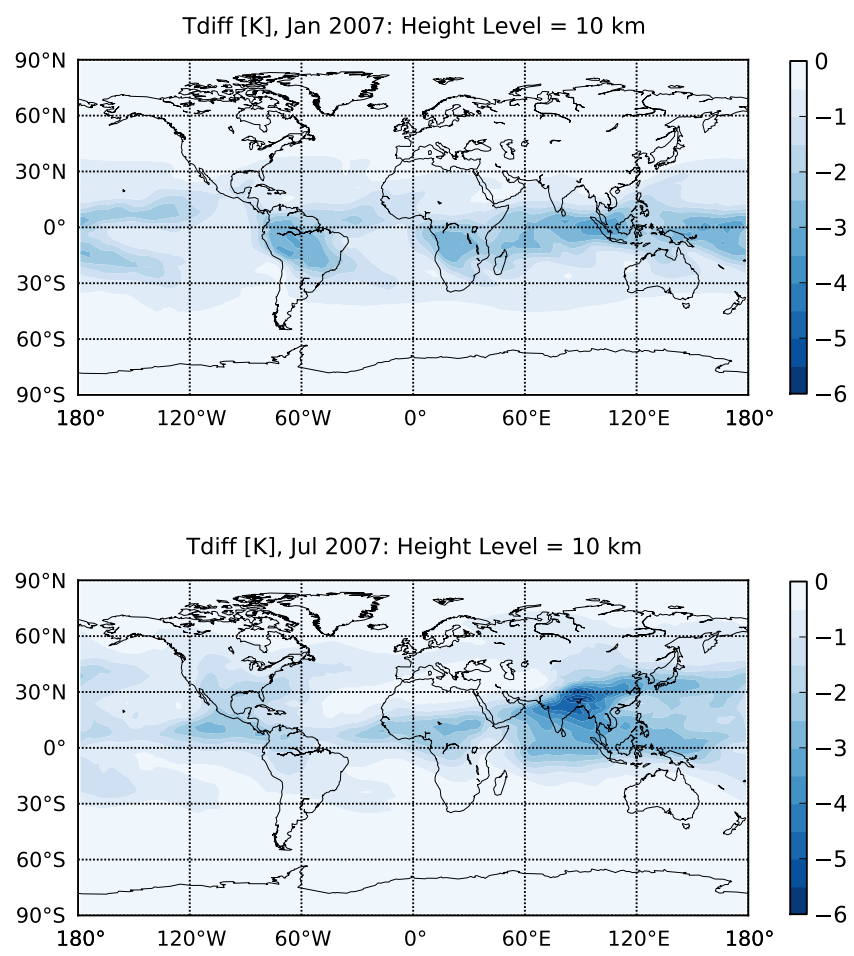

Figure 3. Difference between dry and physical temperature at a geopotential height of $10 \mathrm{~km}$ for January 2007 (top) and July 2007 (bottom).

temperature differences were studied, where dry temperature is always lower than physical temperature; see also, Foelsche et al. (2008a) and Scherllin-Pirscher et al. (2011). The discrepancy between dry and physical temperature is small for regions with negligible water vapor, but gets more significant with increasing water vapor. In the next section the analysis method for the transition height between dry and moist air will be introduced.

\subsection{Analysis of data}

With the goal to identify the height region, where dry temperature is a good proxy for physical temperature, we investigated temperature differences between dry and physical temperature,

$T_{\text {diff }}=T_{\text {dry }}-T$,

and analyzed specific values of $T_{\text {diff }}=-0.1,-0.05,-0.03$, and $-0.02 \mathrm{~K}$, where each temperature difference is connected with a specific altitude (we call it also "transition line" between dry and moist air). We do not show results for $T_{\text {diff }}=-0.01 \mathrm{~K}$ since small water vapor fluctuations sometimes yield this specific value several times, with the consequence of more than one transition height in a latitude zone.

Based on ECMWF fields, we started our analysis with $10^{\circ}$ zonal climatological fields (Sect. 3.1) to analyze the dependence of $T_{\text {diff }}$ on latitude and season. In addition, we investigated its longitudinal dependencies. In Sect. 3.2, we analyzed $60^{\circ}$ longitudinal bins - i.e., from -180 to $-120^{\circ}$, -120 to $-60^{\circ},-60$ to $0^{\circ}, 0$ to $60^{\circ}, 60$ to $120^{\circ}$, and 120 to $180^{\circ}$ - and selected the bin which showed the highest transition line, in order to obtain a conservative estimate.

Based on CMIP5 data, we studied possible trends of the transition lines. Since we observed an approximately linear increase of the transition lines with time, we studied linear trends on a $95 \%$ confidence level, estimated by the method of least squares, using the Breusch-Godfrey test (Godfrey, 1988). The trends were evaluated for $10^{\circ}$ zonal mean climatological fields for a period from 2006 to 2050. In general, natural effects such as ENSO (El Niño-Southern Oscillation), or QBO (quasi-biennial oscillation), only play a negligible role in such long-term-trend studies. However, natural variability can have an impact in the linear regression analysis through the starting year and the end year. Hence, we tested the sensitivity of the start and end years by analyzing the trends in a period of 40 years, starting 2006, and moving ahead 1 year, until 2010. Results showed to be insensitive among this test, and also when comparing the trend results to the trend results for the complete period of 45 years. In this analysis the following two different kinds of trends were analyzed:

1. We studied the trend of the transition lines in height for the fixed temperature differences $T_{\text {diff }}=-0.1,-0.05$, -0.03 , and $-0.02 \mathrm{~K}$ from 2006 until 2050.

2. We evaluated dry temperature trends, physical temperature trends, and their differences for the years 2006-2050. In case of the temperature trend differences (Temp Trend Diff) we show results for Temp Trend Diff $=-0.1,-0.05$, and $-0.02 \mathrm{~K}$.

\section{Current state of the atmosphere and future projections}

\subsection{Qualitative understanding of dry to physical temperature differences}

We started our analysis by calculating $T_{\text {diff }}$ according to Eq. (7), for monthly mean $10^{\circ}$ climatological ECMWF fields. As an example, Fig. 1 shows the results for 4 months: January, April, July, and October 2007. The plots illustrate how differences between dry and physical temperature increase with decreasing height and increasing humidity, showing a clear seasonal dependence. For example, temperature differences larger in magnitude than $6 \mathrm{~K}$ are found at altitudes below $8 \mathrm{~km}$, illustrating seasonal dependent maxima. In January (southern summer) the temperature differences show maxima shifted towards the Southern Hemisphere, while July (northern summer) shows maxima shifted towards the Northern Hemisphere. Data in April and October are essentially symmetric. The colored contour lines 

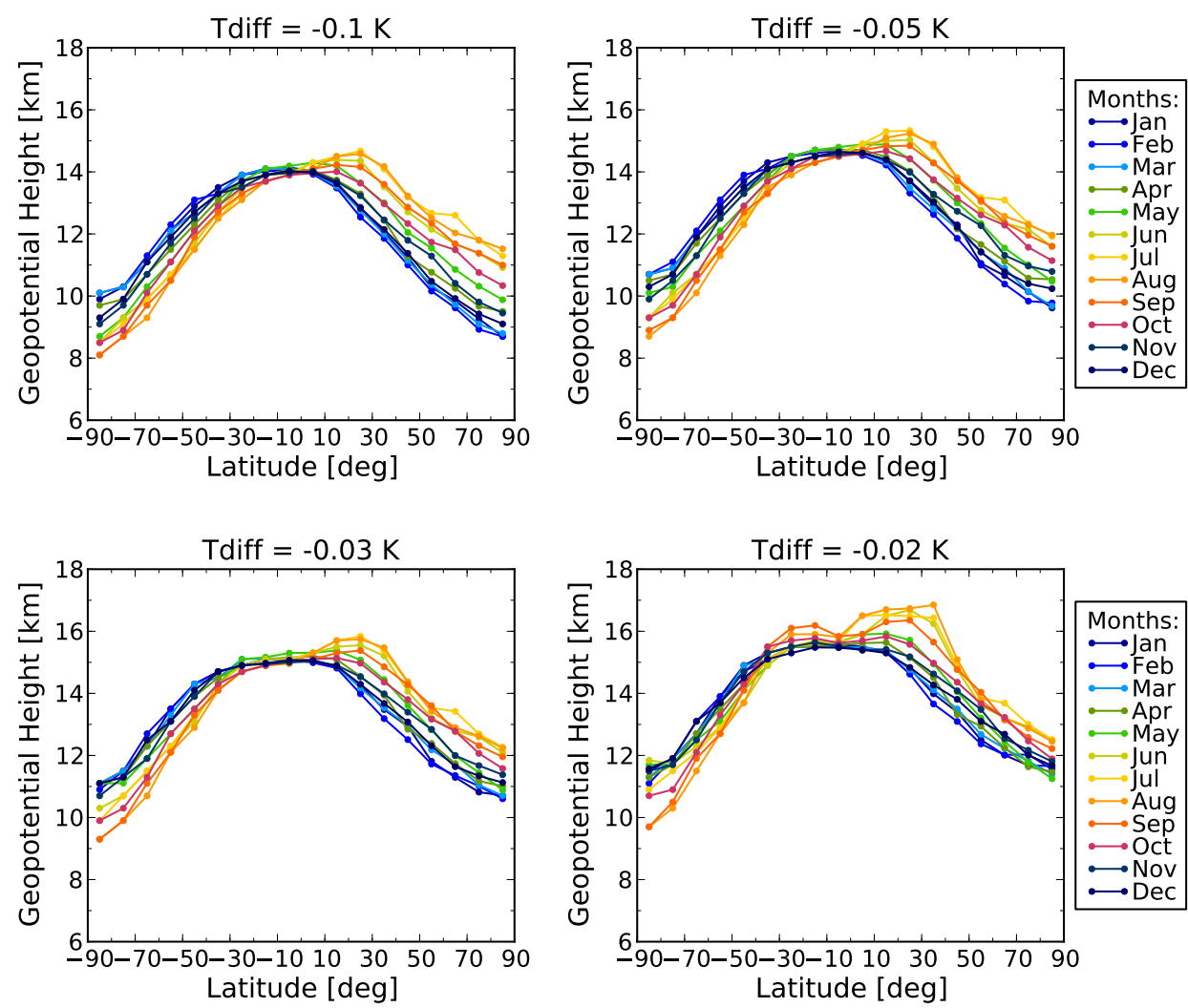

Figure 4. Calculated maxima (solid lines) from 2006 to 2010 of $T_{\text {diff }}=-0.1,-0.05,-0.03$, and -0.02 , for every month.

highlight temperature differences of $-0.1,-0.05,-0.03$, and $-0.02 \mathrm{~K}$. As an example, maximum temperature differences of $0.02 \mathrm{~K}$ (red line) occur in the tropical region between about 15 and $16 \mathrm{~km}$, and at high latitudes between 10 and $12 \mathrm{~km}$.

Next we studied the dependence of temperature differences on time and latitude (Fig. 2) based on two fixed values, $T_{\text {diff }}=-0.1 \mathrm{~K}$ and $T_{\text {diff }}=-0.02 \mathrm{~K}$, for 2006-2010. Figure 2 distinctively shows the expected seasonal cycle, which is highly pronounced for high latitudes and decreases towards the tropics, where seasonal variations are small. Maxima in both hemispheres are found during the respective summer months. Overall, results for $T_{\text {diff }}=-0.1 \mathrm{~K}$ (left column) range from about 7.5 to $14 \mathrm{~km}$. For $T_{\text {diff }}=-0.02 \mathrm{~K}$ the range extends from about 10 to $16 \mathrm{~km}$ in the Northern Hemisphere and from about 9 to $15.5 \mathrm{~km}$ in the Southern Hemisphere. The seasonal variation is more pronounced in the Northern Hemisphere, where the distinct seasonal temperature cycle typically causes a strong seasonal humidity cycle as well. Following the discussion in Scherllin-Pirscher et al. (2011) we can see that the magnitude of $T_{\text {diff }}$ depends primarily on specific humidity, and hence it is directly related to the seasonal cycle.

Figures 1 and 2 give a first impression how monthly mean differences between dry and physical temperature depend on height, latitude, and season. Next we go into more detail, providing a sort of "guide line" for determining down to which height dry temperature profiles can safely be analyzed in current atmospheric conditions.

\subsection{Spatial characteristics of dry to physical temperature differences}

So far we investigated only temperature differences dependent on latitude, neglecting longitudinal variations. Now we also analyze the longitudinal dependence. Figure 3 shows the geographical distribution of differences between dry and physical temperature at geopotential height $z_{\mathrm{g}}=10 \mathrm{~km}$, for a $2.5^{\circ} \times 2.5^{\circ}$ ECMWF monthly mean analysis field. The top plot illustrates results for January 2007, the bottom plot for July 2007. $T_{\text {diff }}$ shows clear dependencies on latitude and longitude, as well as seasonal differences (January, July). Especially in July, we find evidence of the monsoon season over India $\left(60-120^{\circ} \mathrm{E}\right)$. Hence, maximum temperature differences will be found in this particular region. In contrast, the other regions show smaller temperature differences (e.g., $60^{\circ} \mathrm{W}-$ $0^{\circ}$ ). Because of the spatial dependence of humidity in the atmosphere, we decided to analyze the fields additionally with a $10^{\circ} \times 60^{\circ}$ binning.

With the goal of providing a boundary criterion for the transition height between moist and dry air, we plot in Fig. 4 the heights of $T_{\text {diff }}=-0.1,-0.05,-0.03$, and $-0.02 \mathrm{~K}$, 

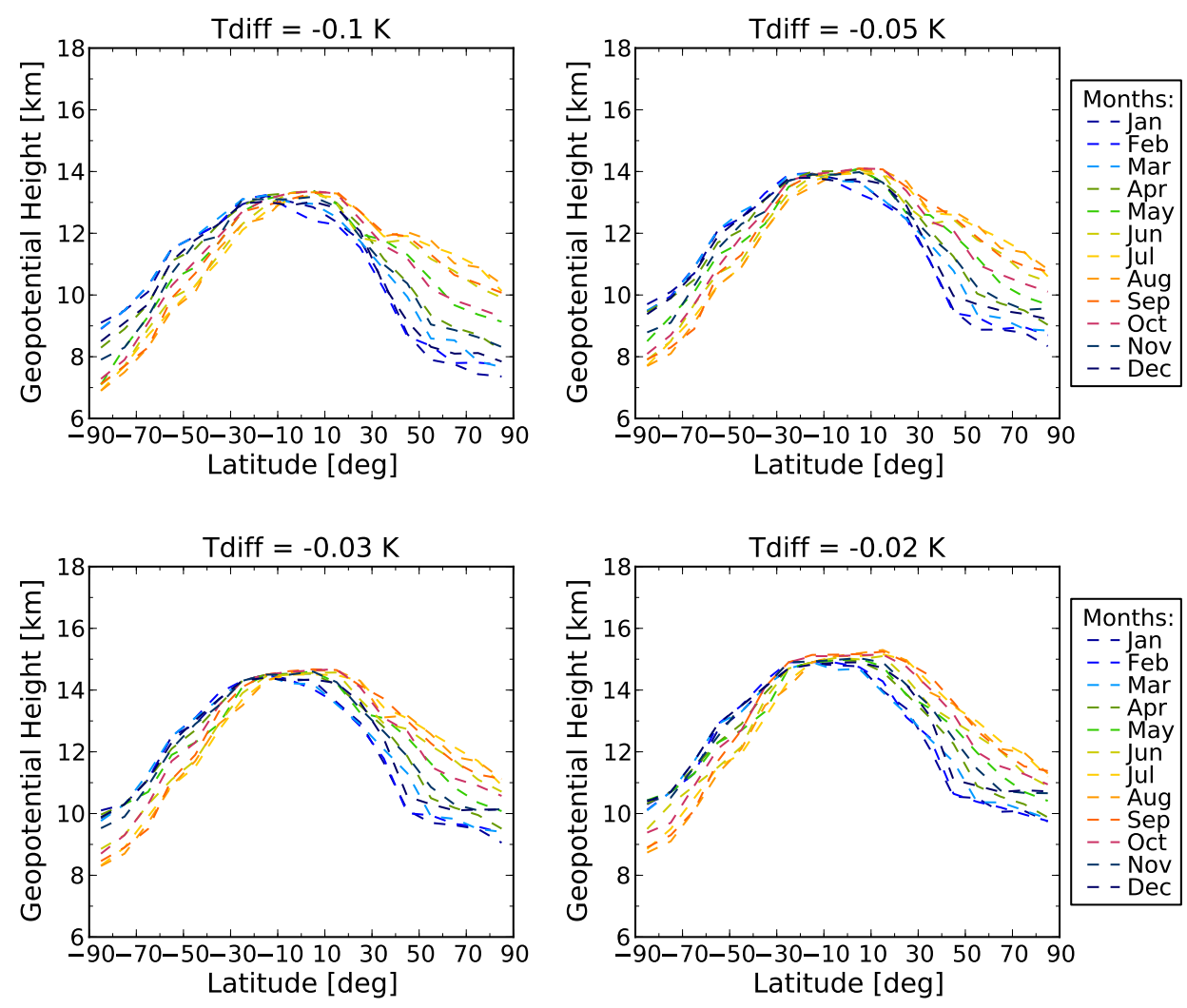

Figure 5. Calculated minima (dashed lines) from 2006 to 2010 of $T_{\text {diff }}=-0.1,-0.05,-0.03$, and $-0.02 \mathrm{~K}$, for every month.

dependent on latitude and month. To obtain these heights we chose the $10^{\circ} \times 60^{\circ}$ longitude bin with maximum humidity in the air from 5 years (2006-2010), investigating every month and every $10^{\circ}$ latitude band, aiming to obtain the highest cutoff values and, hence, a safe estimate for the transition line. Similar to Fig. 1, smaller temperature differences are found at higher altitudes. As expected, northern summer months (plotted in warm colors) showed maximum altitudes in the Northern Hemisphere, reflecting the increase in absolute humidity with increasing temperature. Furthermore all plots exhibited an additional bump for the northern latitudes, arising from the Asian monsoon. The monsoon season leads to additional water vapor in the air, raising the height of the studied transition line at low latitudes.

Furthermore, we plotted in Fig. 5 the minimum value of every bin $\left(10^{\circ} \times 60^{\circ}\right)$ out of 5 years (dashed lines), in order to illustrate the maximum to minimum variation for a given latitude band. It is typically $1 \mathrm{~km}$ and occasionally reaches $2 \mathrm{~km}$. Zonal mean results (not shown) lie in-between the maximum and minimum values.

We provided in Tables 2 and 3 a list of transition heights from Figs. 4 and 5, for January and July, respectively, for $T_{\text {diff }}=-0.1 \mathrm{~K}$. Additionally, we supplied information about the corresponding longitude sector and the year, for the maximum and minimum cases. For January we found for the southern low-latitudes maxima (about $14 \mathrm{~km}$ ) between $120^{\circ} \mathrm{E}$ and $180^{\circ} \mathrm{E}$, reflecting the influence of the Pacific warm pool. For July we found maxima (about $14.5 \mathrm{~km}$ ) from $20^{\circ} \mathrm{S}$ to $40^{\circ} \mathrm{N}$ in the sector $60-120^{\circ} \mathrm{E}$ (summer monsoon; see Fig. 3). Minima for low latitudes (about $13 \mathrm{~km}$ ) are mainly found in the sector $120-180^{\circ} \mathrm{W}$ (eastern Pacific). For January, at low and middle latitudes maxima mainly occurred for 2007, which might be due to a positive ENSO phase. No strong temporal patterns are found for July.

\subsection{Climate change and its impact on dry temperature profiles}

We discuss trends in absolute humidity, by analyzing differences between dry and physical temperature for all CMIP5 models, using $10^{\circ}$ zonal mean climatological fields. We keep in mind that longitudinal variations are on average about $1 \mathrm{~km}$ (cf. Figs. 4, 5), resulting in an about $0.5 \mathrm{~km}$ difference for zonal mean fields.

Altogether, we studied a set of 38 models. The initial analysis of the models is similar to the analysis of the ECMWF monthly mean climatological fields. First of all we found that the overall features (annual cycle and latitudinal variability) of the time series are similar for all GCMs. As a representative example for the "max 8 " models with highest transition lines we show in Fig. 6 a time series of $T_{\text {diff }}=-0.1 \mathrm{~K}$, for the model BCC-CSM1.1(m) (Xin et al., 2013), from 

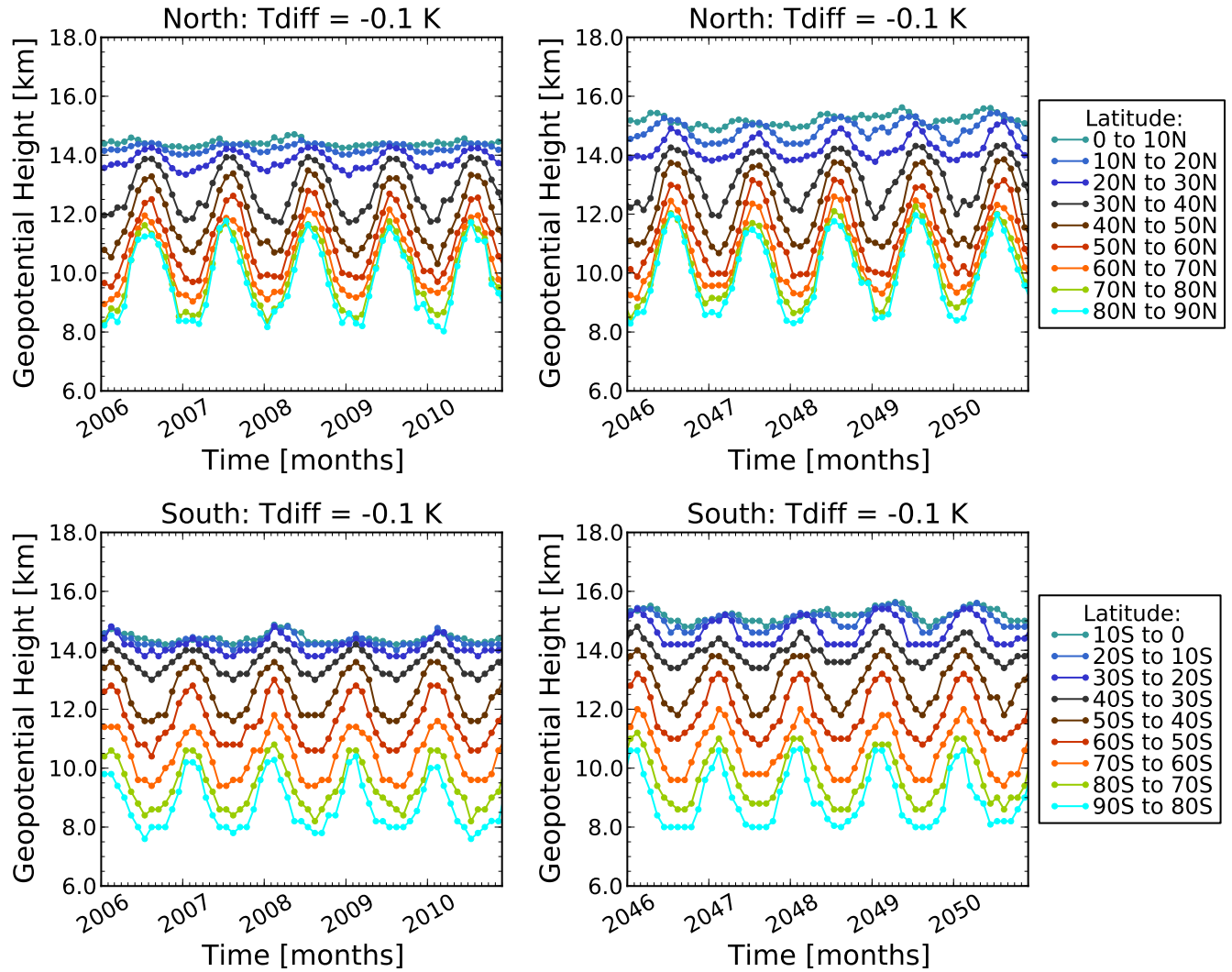

Figure 6. Temporal evolution of differences between dry and physical temperature $\left(T_{\text {diff }}\right)$ for the model BCC-CSM1.1(m) from the Beijing Climate Center. The left column shows $10^{\circ}$ zonal mean climatological fields from 2006 to 2010 and the right column from 2046 to 2050 , for $T_{\text {diff }}=-0.1 \mathrm{~K}$.

Table 2. January: maximum height, corresponding longitude sector and year and minimum height, corresponding longitude sector and year for $T_{\text {diff }}=-0.1 \mathrm{~K}$.

\begin{tabular}{rrrrrrr}
\hline Latitude & Max. height & Long. sector & Year & Min. height & Long. sector & Year \\
\hline-90 to $-80^{\circ}$ & 9.9 & -120 to $-60^{\circ}$ & 2007 & 9.1 & 0 to $60^{\circ}$ & 2008 \\
-80 to $-70^{\circ}$ & 10.3 & -120 to $-60^{\circ}$ & 2007 & 9.5 & 60 to $120^{\circ}$ & 2006 \\
-70 to $-60^{\circ}$ & 11.1 & -120 to $-60^{\circ}$ & 2007 & 10.1 & 0 to $60^{\circ}$ & 2006 \\
-60 to $-50^{\circ}$ & 12.1 & -180 to $-120^{\circ}$ & 2006 & 11.5 & -120 to $-60^{\circ}$ & 2006 \\
-50 to $-40^{\circ}$ & 12.9 & -60 to $0^{\circ}$ & 2007 & 11.9 & 60 to $120^{\circ}$ & 2006 \\
-40 to $-30^{\circ}$ & 13.5 & -60 to $0^{\circ}$ & 2007 & 12.3 & 60 to $120^{\circ}$ & 2006 \\
-30 to $-20^{\circ}$ & 13.9 & 120 to $180^{\circ}$ & 2007 & 12.9 & -60 to $0^{\circ}$ & 2006 \\
-20 to $-10^{\circ}$ & 14.1 & 120 to $180^{\circ}$ & 2007 & 13.2 & -120 to $-60^{\circ}$ & 2006 \\
-10 to $0^{\circ}$ & 14.1 & 120 to $180^{\circ}$ & 2007 & 13.0 & -180 to $-120^{\circ}$ & 2009 \\
0 to $10^{\circ}$ & 14.0 & 120 to $180^{\circ}$ & 2007 & 12.8 & -180 to $-120^{\circ}$ & 2009 \\
10 to $20^{\circ}$ & 13.6 & 60 to $120^{\circ}$ & 2007 & 12.3 & -180 to $-120^{\circ}$ & 2006 \\
20 to $30^{\circ}$ & 12.8 & 60 to $120^{\circ}$ & 2007 & 11.7 & -180 to $-120^{\circ}$ & 2006 \\
30 to $40^{\circ}$ & 12.0 & -120 to $-60^{\circ}$ & 2007 & 10.4 & -180 to $-120^{\circ}$ & 2006 \\
40 to $50^{\circ}$ & 11.2 & -60 to $0^{\circ}$ & 2007 & 8.7 & 120 to $180^{\circ}$ & 2010 \\
50 to $60^{\circ}$ & 10.2 & -60 to $0^{\circ}$ & 2006 & 7.9 & 120 to $180^{\circ}$ & 2008 \\
60 to $70^{\circ}$ & 9.8 & -60 to $0^{\circ}$ & 2010 & 7.7 & 120 to $180^{\circ}$ & 2008 \\
70 to $80^{\circ}$ & 9.2 & -60 to $0^{\circ}$ & 2010 & 7.4 & 120 to $180^{\circ}$ & 2008 \\
80 to $90^{\circ}$ & 8.7 & 0 to $60^{\circ}$ & 2006 & 7.3 & -180 to $-120^{\circ}$ & 2007 \\
\hline
\end{tabular}


Table 3. July: maximum height, corresponding longitude sector and year and minimum height, corresponding longitude sector and year for $T_{\text {diff }}=-0.1 \mathrm{~K}$.

\begin{tabular}{rrrrrrr}
\hline Latitude & Max. height & Long. sector & Year & Min. height & Long. sector & Year \\
\hline-90 to $-80^{\circ}$ & 8.5 & -120 to $-60^{\circ}$ & 2007 & 6.9 & 60 to $120^{\circ}$ & 2010 \\
-80 to $-70^{\circ}$ & 9.1 & -120 to $-60^{\circ}$ & 2007 & 7.7 & 0 to $60^{\circ}$ & 2006 \\
-70 to $-60^{\circ}$ & 9.9 & -120 to $-60^{\circ}$ & 2007 & 8.7 & 60 to $120^{\circ}$ & 2006 \\
-60 to $-50^{\circ}$ & 10.7 & -120 to $-60^{\circ}$ & 2007 & 9.5 & 60 to $120^{\circ}$ & 2008 \\
-50 to $-40^{\circ}$ & 11.5 & -120 to $-60^{\circ}$ & 2007 & 10.3 & 60 to $120^{\circ}$ & 2006 \\
-40 to $-30^{\circ}$ & 12.5 & -180 to $-120^{\circ}$ & 2007 & 11.1 & 60 to $120^{\circ}$ & 2006 \\
-30 to $-20^{\circ}$ & 13.3 & 120 to $180^{\circ}$ & 2009 & 12.1 & 0 to $60^{\circ}$ & 2006 \\
-20 to $-10^{\circ}$ & 13.7 & 60 to $120^{\circ}$ & 2006 & 12.7 & -180 to $-120^{\circ}$ & 2006 \\
-10 to $0^{\circ}$ & 13.9 & 60 to $120^{\circ}$ & 2006 & 13.1 & -180 to $-120^{\circ}$ & 2008 \\
0 to $10^{\circ}$ & 14.3 & 60 to $120^{\circ}$ & 2006 & 13.2 & -180 to $-120^{\circ}$ & 2008 \\
10 to $20^{\circ}$ & 14.5 & 60 to $120^{\circ}$ & 2006 & 13.1 & -180 to $-120^{\circ}$ & 2008 \\
20 to $30^{\circ}$ & 14.6 & 60 to $120^{\circ}$ & 2010 & 12.7 & -180 to $-120^{\circ}$ & 2008 \\
30 to $40^{\circ}$ & 14.1 & 60 to $120^{\circ}$ & 2010 & 11.9 & 0 to $60^{\circ}$ & 2006 \\
40 to $50^{\circ}$ & 13.2 & 120 to $180^{\circ}$ & 2008 & 11.9 & 0 to $60^{\circ}$ & 2008 \\
50 to $60^{\circ}$ & 12.7 & 120 to $180^{\circ}$ & 2008 & 11.6 & -60 to $0^{\circ}$ & 2009 \\
60 to $70^{\circ}$ & 12.6 & 120 to $180^{\circ}$ & 2010 & 11.3 & -60 to $0^{\circ}$ & 2009 \\
70 to $80^{\circ}$ & 11.8 & 120 to $180^{\circ}$ & 2010 & 10.9 & -120 to $-60^{\circ}$ & 2008 \\
80 to $90^{\circ}$ & 11.2 & 120 to $180^{\circ}$ & 2007 & 10.1 & 60 to $120^{\circ}$ & 2010 \\
\hline
\end{tabular}

the Beijing Climate Center (http://bcc.cma.gov.cn/bcccsm/ $\mathrm{htm} /$ ). The plot shows $T_{\text {diff }}$ from the years 2006 to 2010 and from 2046 until 2050 for the Northern Hemisphere and the Southern Hemisphere. As in Fig. 2, we find for $T_{\text {diff }}$ a seasonal dependence, ranging from 8 to $14.5 \mathrm{~km}$ in the Northern Hemisphere and from 7.5 to $15.0 \mathrm{~km}$ in the Southern Hemisphere, for 2006-2010. The panels on the right side of Fig. 6 (2046-2050) show the effect of climate change, leading to a distinct rise in the height of transition lines. For northern latitudes $T_{\text {diff }}$ ranges from 8.5 to $15.5 \mathrm{~km}$ and for southern latitudes from 8 to $15.5 \mathrm{~km}$. Hence, at high latitudes the transition line rose by $0.5 \mathrm{~km}$, while for low latitudes by $1 \mathrm{~km}$. The rise of the height of the transition line is intensified at low latitudes, since the effect of increasing humidity is strongest there.

Next, in Fig. 7, we show the results for $T_{\text {diff }}=-0.1 \mathrm{~K}$, for all CMIP5 models, for January and July. The height was calculated as the maximum of the first 5 years (2006-2010) and the maximum of the last 5 years (2046-2050), plotted dependent on latitude. Figure 7 provided the basis from which we chose the subset of models, showing the highest values of the transition lines. Figure 7 shows three important features. First, we observed for all models the seasonal dependence of the transition lines; i.e., for January low-latitude maxima are slightly shifted towards the Southern Hemisphere, while for July they shifted towards the Northern Hemisphere. At high latitudes, maxima are higher in the summer hemisphere than in the winter hemisphere. Second, we observed a lift of the height of the transition lines for 2046-2050, compared to 2006-2010. And third, by comparing the behavior of all models, we saw that the range of the transition lines is
1-2 $\mathrm{km}$. The choice of the subset of models with maximum humidity and, hence, maximum transition lines was not an easy task. As one can see in Fig. 7, the order of models at the upper boundary depends on the temperature difference, latitude, and year. We decided to choose models with the highest humidity content at low latitudes, based on $T_{\text {diff }}=-0.1 \mathrm{~K}$. The selected models are highlighted in Table 1.

In Fig. 8 we show trends of the transition lines per decade, for the selected subset ("max 8") of CMIP5 models. From top to bottom, we plotted $T_{\text {diff }}=-0.1 \mathrm{~K}, T_{\text {diff }}=-0.05 \mathrm{~K}$, and $T_{\text {diff }}=-0.03 \mathrm{~K}$, comparing January and July. We can observe three things: first, the trends are very similar for all studied temperature differences, hence the specific cutoff criterion does not play a dominant role for this trend study. Second, the trend values spread quite uniformly, approximately $150 \mathrm{~m} \mathrm{decade}^{-1}$, showing only a moderate latitudinal dependence. There is a tendency to lower values in the respective winter polar regions, most pronounced for July, where trend values decrease to about $50 \mathrm{~m} \mathrm{decade}^{-1}$ at southern high latitudes. Third, most individual model trends lie between 50 and $250 \mathrm{~m} \mathrm{decade}^{-1}$. For completeness, we studied the trends in the whole set of 38 models (not shown) and found very consistent results, with average trend values of about $150 \mathrm{~m} \mathrm{decade}^{-1}$ and a similar range as in the "max 8 " ensemble.

In this analysis we furthermore studied the trends in physical and dry temperature. Figure 9 shows, for January and July, altitude vs. height plots of physical temperature trends, dry temperature trends, and their differences, based again on the model BCC-CSM1.1(m) from the Beijing Climate Center. For physical temperature, positive trends dominate in the 

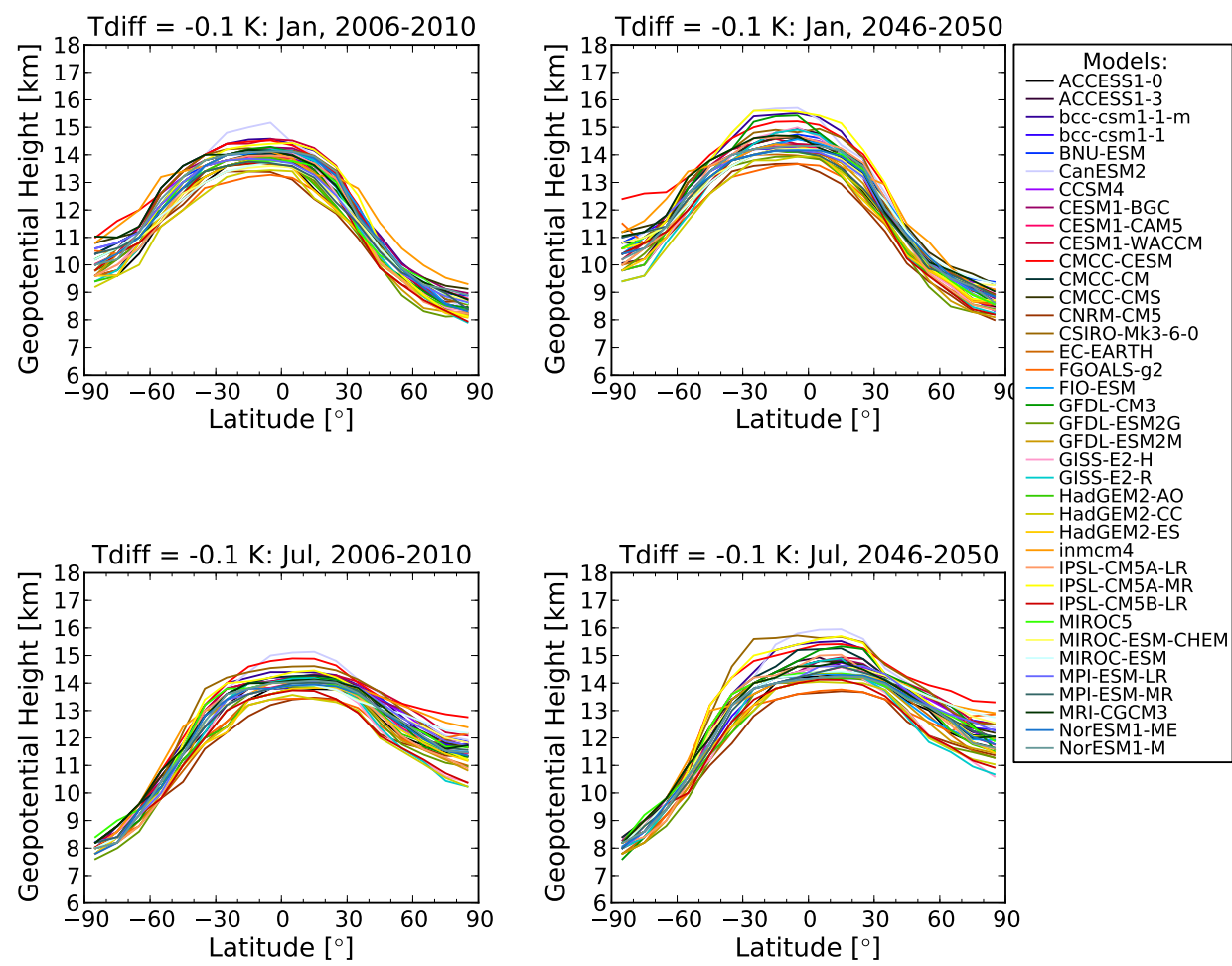

Figure 7. Maximum height of $T_{\text {diff }}=-0.1 \mathrm{~K}$ for all models, from 2006 to 2010 (left column) and 2046 to 2050 (right column), for January (top row) and July (bottom row).
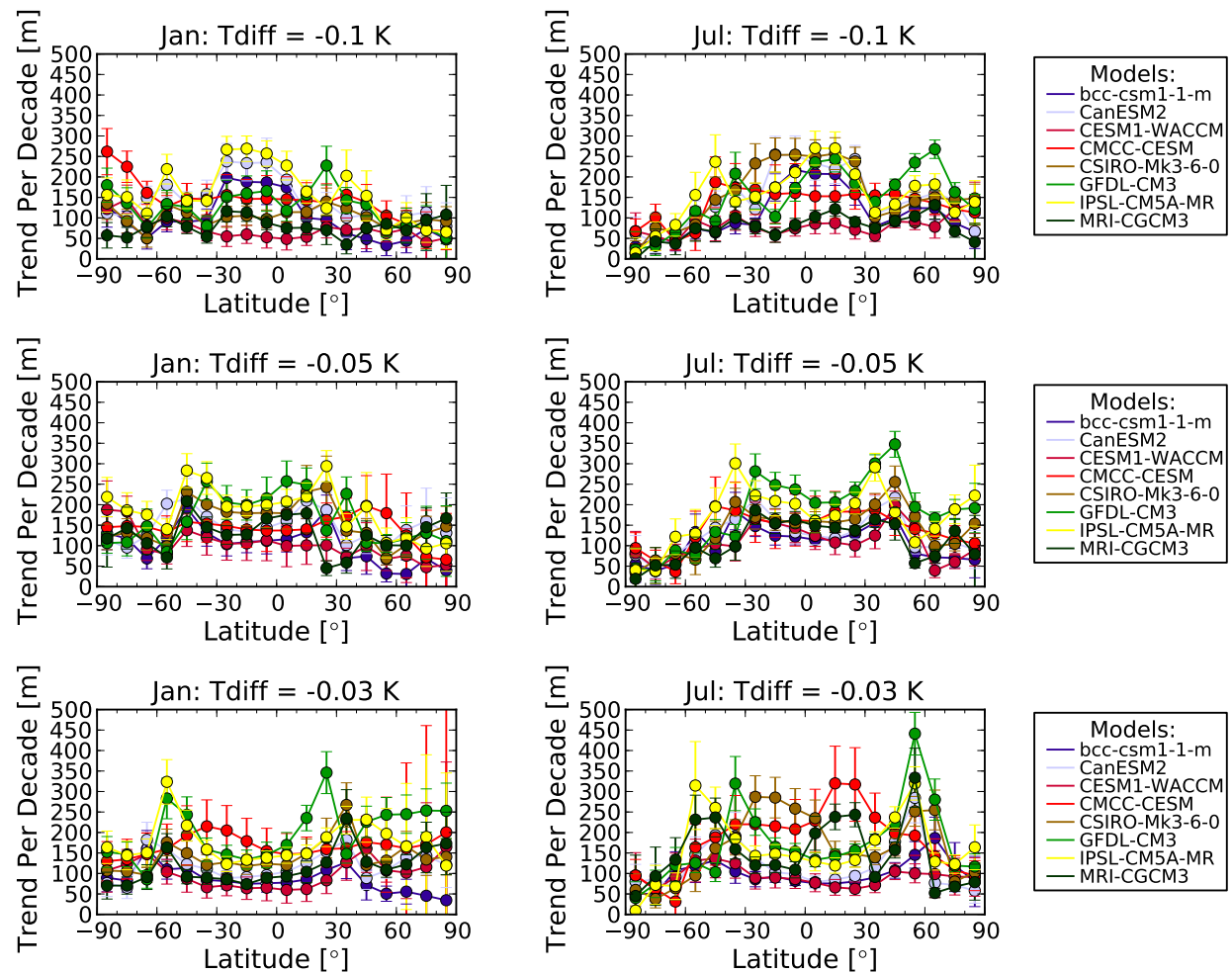

Figure 8. Height increase per decade (linear trend) and $95 \%$ confidence interval for $T_{\text {diff }}=-0.1 \mathrm{~K}$ (top), $T_{\text {diff }}=-0.05 \mathrm{~K}$ (middle), and $T_{\text {diff }}=-0.03 \mathrm{~K}$ (bottom) for January (left) and July (right), for the "max 8" CMIP5 models. 
Trend Per Decade [K], January
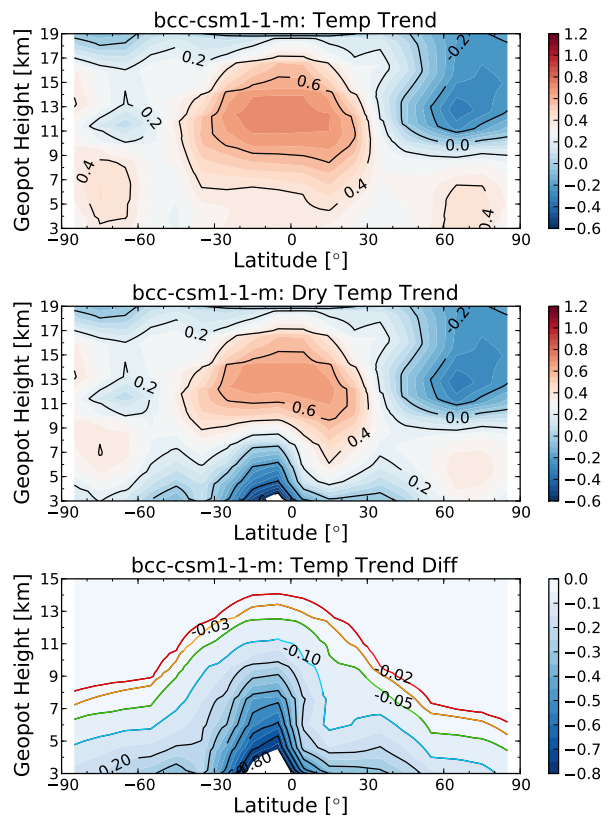

Trend Per Decade [K], July
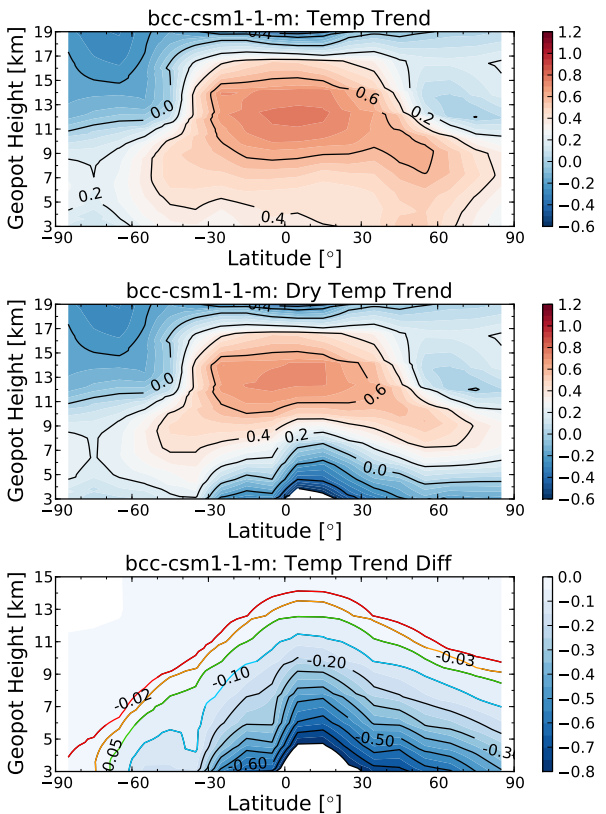

Figure 9. Physical temperature trend per decade (top), dry temperature trend per decade (middle), and difference between dry and physical temperature trend per decade (bottom) for the CMIP5 model BCC-CSM1.1(m) from the Beijing Climate Center, for January (left) and July (right).

troposphere, with maxima at approximately $12 \mathrm{~km}$ at low latitudes. In the lower stratosphere we find negative trends, most pronounced in the respective winter polar regions. Dry temperature trends at high altitudes are virtually the same but at low altitudes the trends in dry temperature become negative, in contrast to the physical temperature trends, since the modeled increase in water vapor overcompensates the moderate increase in physical temperature. This effect results in the familiar trend pattern of trend differences (dry temperature trend minus physical temperature trend), with highest values in humid regions and very low values (less than $-0.02 \mathrm{~K} \mathrm{decade}^{-1}$ ) above about $6 \mathrm{~km}$ (high-latitude winter) and about $14 \mathrm{~km}$ in the tropics. It is interesting to relate the trend differences to physical temperature trends. For example, at $11 \mathrm{~km}$ geopotential height, $0^{\circ}$ latitude, we find in January a trend difference of about $-0.1 \mathrm{~K} \mathrm{decade}^{-1}$ and a physical temperature trend of about $0.7 \mathrm{~K} \mathrm{decade}^{-1}$ leading to a relative error of about $14 \%$ if dry temperature were used as a proxy for physical temperature.

Finally, we investigated at which heights prescribed differences between physical and dry temperature trends have to be expected. Figure 10 shows the results for the "max 8" models for the standard difference values (Temp Trend Diff $=-0.1$, -0.05 , and $-0.02 \mathrm{~K} \mathrm{decade}^{-1}$ ), where we find extremely similar heights for all models in January and July. Selecting a difference of $-0.02 \mathrm{~K} \mathrm{decade}^{-1}$, the corresponding altitude range lies between 6 and $14 \mathrm{~km}$ for January and between 4 and $14 \mathrm{~km}$ for July.

\section{Summary and conclusions}

In this analysis we investigated the influence of humidity on dry temperature profiles. The goal was to give a safe estimate of the altitude down to which monthly mean dry temperature climatologies can be used as a representative for physical temperature. The transition lines were studied based on maximum-allowed temperature differences between dry and physical temperature. Their seasonal, latitudinal, and longitudinal dependencies have systematically been examined. For current atmospheric conditions we find, for $T_{\text {diff }}=-0.1 \mathrm{~K}$, a range of the transition line between about $8 \mathrm{~km}$ at high winter latitudes and up to about $15 \mathrm{~km}$ at low latitudes, see Fig. 4. A list of values for the transition heights dependent on latitude, for January and July, is given in Tables 2 and 3 .

We furthermore extended our study and analyzed the influence of increasing water vapor in the atmosphere on dry temperature, due to climate change. We focused on highend simulations, with the goal of understanding the maximum impact of water vapor on future dry temperature climatologies and trend studies. Data from 38 CMIP5 models have been studied from 2006 until 2050. We observed a mean trend of the increase of the transition lines between dry and moist air of about $150 \mathrm{~m} \mathrm{decade}^{-1}$, with a typical spread between about 50 and $250 \mathrm{~m}$ decade $^{-1}$ amongst all models. The trend values were very similar for all temperature differences. Finally, we also analyzed trends of physical temperature and dry temperature and their differences. For 

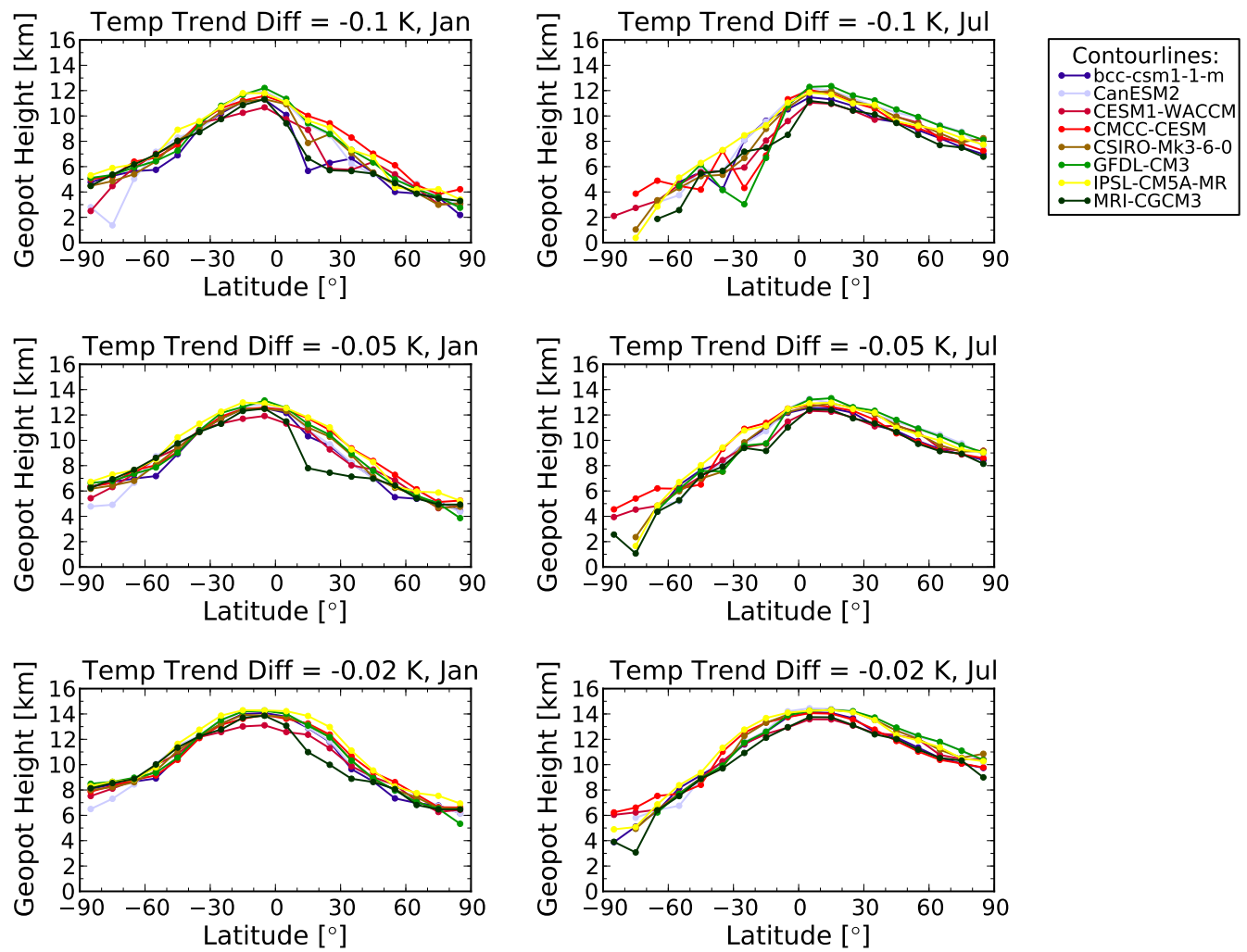

Figure 10. Latitudinal and altitudinal dependence of differences between physical and dry temperature trends for the "max 8" CMIP5 models, for January (left) and July (right), for $-0.1 \mathrm{~K} \mathrm{decade}^{-1}$ (top), $-0.05 \mathrm{~K} \mathrm{decade}^{-1}$ (middle) and $-0.02 \mathrm{~K} \mathrm{decade}^{-1}$ (bottom).

physical temperature positive trends dominated in the troposphere. In the lower stratosphere we found negative trends, most pronounced in the respective winter polar regions. Dry temperature trends at high altitudes were virtually the same, but at low altitudes the trends in dry temperature become negative, since the modeled increase in water vapor overcompensates the moderate increase in physical temperature. While the trend patterns depend on the studied model, the trend differences between dry temperature and physical temperature showed a strong overlap between the models.

This analysis provides a conservative estimate of the domain where it is safe to use dry temperature as representative for physical temperature. The lower boundary of this domain can be expected to rise by about $1 \mathrm{~km}$ over the next 7 decades.

Acknowledgements. We thank the ECMWF for kindly providing analysis data. Furthermore we acknowledge the modeling groups and the WCRP's Working Group on Coupled Modelling (WGCM) for making available the CMIP5 multimodel data set. We especially want to thank A. Prein and M. Jury (ReLoClim group, WEGC) for many fruitful discussions. Furthermore, we are grateful to the Austrian Science Fund (FWF) for funding our work under grant P22293-N21 (BENCHCLIM project). Barbara Scherllin-Pirscher was funded by the FWF project T620-N29 (DYNOCC project). Finally we thank W. De Geeter (WEGC) for his technical support.
Edited by: A. von Engeln

\section{References}

CLIVAR Exchanges: WCRP Coupled Model Intercomparison Project - Phase 5 - CMIP5, 16, 2011.

Danzer, J., Scherllin-Pirscher, B., and Foelsche, U.: Systematic residual ionospheric errors in radio occultation data and a potential way to minimize them, Atmos. Meas. Tech., 6, 2169-2179, doi:10.5194/amt-6-2169-2013, 2013.

Fjeldbo, G., Kliore, A. J., and Eshleman, V. R.: The neutral atmosphere of Venus as studied with the Mariner V radio occultation experiments, Astron. J., 76, 123-140, doi:10.1086/111096, 1971.

Foelsche, U., Borsche, M., Steiner, A. K., Gobiet, A., Pirscher, B., Kirchengast, G., Wickert, J., and Schmidt, T.: Observing upper troposphere lower stratosphere climate with radio occultation data from the CHAMP satellite, Clim. Dynam., 31, 49-65, doi:10.1007/s00382-007-0337-7, 2008a.

Foelsche, U., Kirchengast, G., Steiner, A. K., Kornblueh, L., Manzini, E., and Bengtsson, L.: An observing system simulation experiment for climate monitoring with GNSS radio occultation data: setup and test bed study, J. Geophys. Res., 113, D11108, doi:10.1029/2007JD009231, 2008b.

Foelsche, U., Scherllin-Pirscher, B., Ladstädter, F., Steiner, A. K., and Kirchengast, G.: Refractivity and temperature climate records from multiple radio occultation satellites consis- 
tent within $0.05 \%$, Atmos. Meas. Tech., 4, 2007-2018, doi:10.5194/amt-4-2007-2011, 2011.

Fritzer, J., Kirchengast, G., and Pock, M.: End-to-End Generic Occultation Performance Simulation and Processing System Version 5.5 (EGOPS5.5) Software User Manual, Tech. rep., University of Graz, Austria, WEGC and IGAM, WEGC-EGOPS2009-TR01, 2009.

Godfrey, L. G.: Misspecification Tests in Econometrics, Cambridge University Press, Cambridge, 1988.

Gorbunov, M. E.: Canonical transform method for processing radio occultation data in the lower troposphere, Radio Sci., 37, 1076, doi:10.1029/2000RS002592, 2002.

Hajj, G. A., Ao, C. O., Iijima, P. A., Kuang, D., Kursinski, E. R., Mannucci, A. J., Meehan, T. K., Romans, L. J., de la Torre Juarez, M., and Yunck, T. P.: CHAMP and SAC-C atmospheric occultation results and intercomparisons, J. Geophys. Res., 109, D06109, doi:10.1029/2003JD003909, 2004.

Hawkins, E. and Sutton, R.: The potential to narrow uncertainty in regional climate predictions, B. Am. Meteorol. Soc., 90, 10951107, 2009.

Healy, S. B. and Eyre, J. R.: Retrieving temperature, water vapour and surface pressure information from refractive-index profiles derived by radio occultation: a simulation study, Q. J. Roy. Meteor. Soc., 126, 1661-1683, 2000.

Ho, S.-P., Hunt, D., Steiner, A. K., Mannucci, A. J., Kirchengast, G., Gleisner, H., Heise, S., von Engeln, A., Marquardt, C., Sokolovskiy, S., Schreiner, W., Scherllin-Pirscher, B., Ao, C., Wickert, J., Syndergaard, S., Lauritsen, K. B., Leroy, S., Kursinski, E. R., Kuo, Y.-H., Foelsche, U., Schmidt, T., and Gorbunov, M.: Reproducibility of GPS radio occultation data for climate monitoring: profile-to-profile inter-comparison of CHAMP climate records 2002 to 2008 from six data centers, J. Geophys. Res., 117, D18111, doi:10.1029/2012JD017665, 2012.

Jensen, A. S., Lohmann, M. S., Benzon, H.-H., and Nielsen, A. S.: Full spectrum inversion of radio occultation signals, Radio Sci., 38, 1040, doi:10.1029/2002RS002763, 2003.

Knutti, R. and Sedlacek, J.: Robustness and uncertainties in the new CMIP5 climate model projections, Nature Climate Change, 3, 369-373, doi:10.1038/nclimate1716, 2013.

Kursinski, E. R., Hajj, G. A., Schofield, J. T., Linfield, R. P., and Hardy, K. R.: Observing Earth's atmosphere with radio occultation measurements using the Global Positioning System, J. Geophys. Res., 102, 23429-23465, doi:10.1029/97JD01569, 1997.

Lackner, B. C., Steiner, A. K., and Kirchengast, G.: Where to see climate change best in radio occultation variables - study using GCMs and ECMWF reanalyses, Ann. Geophys., 29, 2147-2167, doi:10.5194/angeo-29-2147-2011, 2011.

Leroy, S. S., Dykema, J. A., and Anderson, J. G.: Climate benchmarking using GNSS occultation, in: Atmosphere and Climate: Studies by Occultation Methods, edited by: Foelsche, U., Kirchengast, G., and Steiner, A. K., Springer, 287-302, 2006.

Meehl, G. A., Covey, C., Taylor, K. E., Delworth, T., Stouffer, R. J., Latif, M., McAvaney, B., and Mitchell, J. F. B.: The WCRP CMIP3 multimodel dataset: a new era in climate change research, B. Am. Meteorol. Soc., 88, 1383-1394, doi:10.1175/BAMS-88-9-1383, 2007.
Pierce, D. W., Barnett, T. P., Santer, B. D., and Gleckler, P. J.: Selecting global climate models for regional climate change studies, P. Natl. Acad. Sci. USA, 106, 8441-8446, 2009.

Prein, A., Gobiet, A., and Truhetz, H.: Analysis of uncertainty in large scale climate change projections over Europe, Meteorol. Z., 20, 383-395, doi:10.1127/0941-2948/2011/0286, 2011.

Ringer, M. A. and Healy, S. B.: Monitoring twenty-first century climate using GPS radio occultation bending angles, Geophys. Res. Lett., 35, L05708, doi:10.1029/2007GL032462, 2008.

Scherllin-Pirscher, B., Kirchengast, G., Steiner, A. K., Kuo, Y.H., and Foelsche, U.: Quantifying uncertainty in climatological fields from GPS radio occultation: an empirical-analytical error model, Atmos. Meas. Tech., 4, 2019-2034, doi:10.5194/amt-42019-2011, 2011.

Schmidt, T., Wickert, J., and Haser, A.: Variability of the upper troposphere and lower stratosphere observed with GPS radio occultation bending angles and temperatures, Adv. Space Res., 46, 150-161, doi:10.1016/j.asr.2010.01.021, 2010.

Schreiner, W., Rocken, C., Sokolovskiy, S., Syndergaard, S., and Hunt, D.: Estimates of the precision of GPS radio occultations from the COSMIC/FORMOSAT-3 mission, Geophys. Res. Lett., 34, L04808, doi:10.1029/2006GL027557, 2007.

Smith, E. and Weintraub, S.: The constants in the equation for atmospheric refractive index at radio frequencies, P. IRE, 41, 10351037, 1953.

Steiner, A. K., Kirchengast, G., Lackner, B. C., Pirscher, B., Borsche, M., and Foelsche, U.: Atmospheric temperature change detection with GPS radio occultation 1995 to 2008, Geophys. Res. Lett., 36, L18702, doi:10.1029/2009GL039777, 2009.

Steiner, A. K., Hunt, D., Ho, S.-P., Kirchengast, G., Mannucci, A. J., Scherllin-Pirscher, B., Gleisner, H., von Engeln, A., Schmidt, T., Ao, C., Leroy, S. S., Kursinski, E. R., Foelsche, U., Gorbunov, M., Heise, S., Kuo, Y.-H., Lauritsen, K. B., Marquardt, C., Rocken, C., Schreiner, W., Sokolovskiy, S., Syndergaard, S., and Wickert, J.: Quantification of structural uncertainty in climate data records from GPS radio occultation, Atmos. Chem. Phys., 13, 1469-1484, doi:10.5194/acp-13-1469-2013, 2013.

Taylor, K. E., Stouffer, R. J., and Meehl, G. A.: A summary of the CMIP5 experiment design, available at: http://cmip-pcmdi.llnl. gov/cmip5/experiment_design.html (last access: March 2013), 2009.

Taylor, K. E., Stouffer, R. J., and Meehl, G. A.: An overview of CMIP5 and the experiment design, B. Am. Meteorol. Soc., 93, 485-489, doi:10.1175/BAMS-D-11-00094.1, 2011.

van Vuuren, D. P., Edmonds, J., Kainuma, M., Riahi, K., Thomson, A., Hibbard, K., Hurtt, G. C., Kram, T., Krey, V., Lamarque, J.F., Masui, T., Meinshausen, M., Nakicenovic, N., Smith, S. J., and Rose S. K.: The representative concentration pathways: an overview, Climatic Change, 109, 5-31, 2011.

Vorob'ev, V. V. and Krasil'nikova, T. G.: Estimation of the accuracy of the atmospheric refractive index recovery from Doppler shift measurements at frequencies used in the NAVSTAR system, Izv. Atmos. Ocean. Phy., 29, 602-609, 1994.

Xin, X., Wu, T., and Zhang, J.: Introduction of CMIP5 experiments carried out with the climate system models of Beijing climate center, Adv. Climate Change Res., 4, 41-49, 2013. 